\title{
Assessment of Adherence to Anti-hypertensive Treatment among Patients Attending a Urban Health Care Facility of a Medical College, Tumkur
}

\author{
Cheluve Gowda GK, Savitha Rani BB*, Krishna lyengar, Venkatesh P, Vinay KS
}

\begin{abstract}
Chronic non-communicable diseases are posing a serious threat to public health throughout the world, irrespective of whether developed and developing and thus deserve to be treated as a global health priority. Hypertension is the leading modifiable risk factor for cardiovascular diseases. Poor compliance to antihypertensive therapies has been linked to a variety of problems, including poor blood pressure control, rehospitalisation and increased healthcare resource utilization. Methodology: This Cross-Sectional study was carried out among all adult hypertensive patients from September to October 2018 visiting Urban Health Training Centre of Sri Siddhartha Medical College. Results: Out of 150 study subjects Majority of them 66 (44\%) were having hypertension for $10-15$ yrs and least $18(12 \%)$ were having Hypertension for $>5$ yrs, 81 (54\%) were Purchasing drugs from Private sectors and others from Government sector. $30(20 \%)$ were taking 2 tablets per day, 109 (72.7\%) were taking 1 tablet per day. 90 (60\%) were having Low adherence, 36 (24\%) were having Medium adherence and 24 (16\%) High adherence for Drugs using Morisky Adherence scale. When we studied association between Adherence to drugs with other Socio-demographic characteristics, we got statistically significant results with Socioeconomic status, residence and Place of Purchase of drugs $(P=0.0)$. Conclusion: Adherence to drugs was found to be low in the present study. The level of adherence to treatment among the participants can be achieved by educating the Patients and creating awareness.

Key words: Hypertension,Adherence, Blood pressure,Complications.
\end{abstract}

\section{INTRODUCTION}

\section{Cheluve Gowda GK' Savitha Rani BB ${ }^{1}$, Krishna lyengar ${ }^{1}$, Venkatesh $\mathrm{P}^{1}$, Vinay $\mathrm{KS}^{2}$}

'Department of Community Medicine Sri Siddhartha Medical College, Tumkur, Karnataka, INDIA.

2Department of General Medicine, Sri Siddhartha Medical College, Tumkur Karnataka, INDIA.

Correspondence

Dr. Savitha Rani BB,

Community Medicine, Sri Siddhartha

Medical College, Tumkur- 572101, Karnataka, INDIA.

Phone no: +91 7892376233

Email: savitharanib@gmail.com

History

- Submission Date: 22-01-19

- Revised Date: 21-02-19

- Accepted Date: 21-05-19

DOI : 10.5530/ijmedph.2019.2.11

Article Available online

http://www.ijmedph.org/v9/i2

\section{Copyright}

(C) 2019 Phcog.Net. This is an openaccess article distributed under the terms of the Creative Commons Attribution 4.0 International license.
Hypertension is one of the major Public Health problem in both the developed and developing countries. Increased blood pressure is a leading risk factor for premature death, stroke and heart disease worldwide. Hypertension is the leading modifiable risk factor for cardiovascular diseases and was the topmost leading risk factor for global disease burden in $2010 .^{1}$

Chronic non-communicable diseases are posing a serious threat to public health throughout the world and thus deserve to be treated as a global health priority. ${ }^{2}$ Hypertension accounts for 7.1 million deaths worldwide every year of which $57 \%$ is due to stroke and $43 \%$ is due to ischemic heart disease. ${ }^{2}$

WHO defines adherence as "the extent to which a person's behaviour in taking medication, following a diet and /or executing lifestyle changes". ${ }^{3}$

World Health Organization (WHO) describes poor adherence as the most important cause of uncontrolled blood pressure and estimates that $50 \%$ of people do not take their antihypertensive medication as prescribed.

The poorest of the people are at the highest risk of developing and dying prematurely from chronic diseases because their exposure to risk is high, whereas their access to health care services is low: "chronic diseases and poverty are interconnected in a vicious cycle". Inability to buy drugs is a major determinant and is significantly associated with poor compliance and poor health outcomes in the developing world. ${ }^{4}$

Non-adherence to the medical regimens is a major concern in the management of patients with chronic illness like hypertension and is a major cause for treatment failure. ${ }^{4,5}$

The present studies is conducted with the aim to assess adherence to drugs in a Hypertensive patients.

\section{METHODOLOGY}

This Cross-Sectional study will be carried out among adult hypertensive patients visiting Urban Health Training Centre (UHTC) of Sri Siddhartha Medical College during September to October 2018.

\section{Sample size}

All Hypertensive Patients attending Urban Health centre during September and October were taken for study.

\section{Cite this article : Gowda CGK, Savitha RBB, lyengar K, Venkatesh P, Vinay KS. Assessment of Adherence to Antihy- pertensive Treatment among Patients Attending a Urban Health Care Facility of a Medical College, Tumkur. Int J Med Public Health. 2019;9(2):42-5.}




\section{Sampling Technique}

Convenient sampling, all the consecutive diabetic subjects who attended Urban Health centre were included during that period.

\section{Method of data collection}

Medication adherence will be measured using the 8 item Morisky Medication Adherence Scale (MMAS-8) consisting of 8 items each of which measures a specific medication taking behaviour. Response categories are yes/no for 7 items and a 5 point Likert response for the last item.

Socio-demographic characteristics will be recorded of all the eligible patients like age, gender, history of duration of hypertension, socioeconomic status, education level using pretested semi structured questionnaire. Questions will also be asked on number and frequency of the drugs and any side effects of drugs as experienced by patient.

Data will be collected by direct face to face interview by using semi structured questionnaire.

The degree of adherence will be determined according to the score resulting from the sum of all the correct answers: high adherence $(8$ points), average adherence ( 6 to $<8$ points) and poor adherence $(<6$ points). In this study, patients will be considered adherent when they have a score equal to eight in the MMAS-8.

\section{Statistical Analysis}

Data thus obtained was coded and entered into Microsoft Excel Work sheet. This was analysed using SPSS 22 version.

Analysis done by descriptive statistics like frequency distribution of the study subjects according to age, sex, marital status, educational status, employment, type of occupation and Socioeconomic status, To find out the association of Adherence of drugs with above factors, chi-square test was applied for each factor. The statistical significance was evaluated at $5 \%$ level of significance.

\section{RESULTS}

\section{Socio-demographic Characterstics}

Out of 150 study subjects majority of them 47 (31.3\%) belongs to 49-58 yrs and least $17(11.3 \%)$ belongs to $29-38$ yrs, 96 (64\%) were Males and $54(36 \%)$ were females, $41(27.3 \%)$ were Non-literate, 60 (40\%) studied till High School and 49 (32.7\%) studied Secondary and above, Most of them 49 (32.7\%) were unemployed and 6 (4\%) were in Professional job, Majority of them 59 (39.3\%) were from Urban slums, 35 (23.3\%) were from rural area and $56(37.3 \%)$ were from Urban area, $56(37.3 \%)$ belongs to Upper lower class and $16(10.7 \%)$ were from Upper middle class (Table 1).

\section{Disease Profile}

Majority of them 66 (44\%) were having hypertension for 10-15 yrs and least 18 (12\%) were having Hypertension for $>5$ yrs (Table 2), 81 (54\%) were Purchasing drugs from Private sectors and others from Government sector (Table 3), 30 (20\%) were taking 2 tablets per day, 109 (72.7\%) were taking 1 tablet per day, $5(3.3 \%)$ were taking 3 tablets per day and 6 (4\%) were taking 4 tablets per day (Table 4 ).

\section{Adherence to drugs}

90 (60\%) were having Low adherence, 36 (24\%) were having Medium adherence and 24 (16\%) High adherence for Drugs using Morisky Adherence scale. (Table 5)

When we studied association between Adherence to drugs with other Socio- demographic characteristics, we got statistically significant results
Table 1: Distribution Study Subjects based on Age.

\begin{tabular}{|c|c|c|}
\hline Determinants & Frequency & Percentage (\%) \\
\hline \multicolumn{3}{|c|}{ Age } \\
\hline $29-38$ & 17 & 11.3 \\
\hline $39-48$ & 38 & 25.3 \\
\hline $49-58$ & 47 & 31.3 \\
\hline $59-68$ & 28 & 18.7 \\
\hline 69 and $>$ & 20 & 13.3 \\
\hline \multicolumn{3}{|c|}{ Gender } \\
\hline Female & 96 & 64.0 \\
\hline Male & 54 & 36.0 \\
\hline \multicolumn{3}{|c|}{ Education } \\
\hline Non-literate & 41 & 27.3 \\
\hline Primary and High School & 60 & 40.0 \\
\hline Secondary School and above & 49 & 32.7 \\
\hline \multicolumn{3}{|l|}{ Occupation } \\
\hline Unemployed & 49 & 32.7 \\
\hline Unskilled & 38 & 25.3 \\
\hline \multicolumn{3}{|c|}{ Semi-skilled } \\
\hline Skilled & 14 & 9.3 \\
\hline Clerical and shop owners & 12 & 8.0 \\
\hline Semi-professional & 19 & 12.7 \\
\hline Professional & 6 & 4.0 \\
\hline \multicolumn{3}{|l|}{ Residence } \\
\hline Urban & 56 & 37.3 \\
\hline Urban Slum & 59 & 39.3 \\
\hline Rural & 35 & 23.3 \\
\hline \multicolumn{3}{|c|}{ Socioeconomic status } \\
\hline Upper class & 32 & 21.3 \\
\hline Upper Middle class & 16 & 10.7 \\
\hline Lower Middle class & 46 & 30.7 \\
\hline Upper Lower class & 56 & 37.3 \\
\hline
\end{tabular}

Table 2: Distribution Study Subjects based on duration of Hypertension.

\begin{tabular}{|ccc|}
\hline Duration of HTN & Frequency & Percent \\
\hline $1-10$ yrs & 137 & 91.3 \\
$10-20$ yrs & 11 & 7.4 \\
$>20$ yrs & 2 & 1.3 \\
Total & 150 & 100.0 \\
\hline
\end{tabular}

Table 3: Distribution Study Subjects based on Purchase of Medicine.

\begin{tabular}{ccc} 
Medicine Purchased & Frequency & Percent \\
\hline Government Pharmacy & 69 & 46.0 \\
Private Pharmacy & 81 & 54.0 \\
Total & 150 & 100.0 \\
\hline
\end{tabular}




\begin{tabular}{|ccc|}
\hline \multicolumn{2}{|c|}{ Table 4: Distribution Study Subjects based on } & Number \\
\hline Number of Tablets taken & Frequency & Percent \\
\hline 1 & 109 & 72.7 \\
2 & 30 & 20.0 \\
3 & 5 & 3.3 \\
4 & 6 & 4.0 \\
Total & 150 & 100.0 \\
\hline
\end{tabular}

\begin{tabular}{|ccc|}
\hline $\begin{array}{c}\text { Table 5: Distribution Study Subjects based on Adherence Scoring. } \\
\text { Adherence }\end{array}$ & Frequency & Percent \\
\hline Low adherence & 90 & 60.0 \\
Medium Adherence & 36 & 24.0 \\
High Adherence & 24 & 16.0 \\
Total & 150 & 100.0
\end{tabular}

Table 6: Distribution of study subjects based on Association of Adherence with Socio-demographic Characteristics.

\begin{tabular}{|c|c|c|c|c|c|c|}
\hline Determinants & Low adherence & Medium adherence & High adherence & Total (\%) & Chi-square value & $p$-value \\
\hline \multicolumn{7}{|c|}{ Age in yrs } \\
\hline $29-38$ & 11 & 4 & 2 & $17(11.3)$ & \multirow{5}{*}{5.2} & \multirow{5}{*}{0.7} \\
\hline $39-48$ & 27 & 8 & 3 & $38(25.3)$ & & \\
\hline $49-58$ & 25 & 11 & 11 & $47(31.3)$ & & \\
\hline $59-68$ & 16 & 7 & 5 & $28(18.6)$ & & \\
\hline 69 and $>$ & 11 & 6 & 3 & $20(13.3)$ & & \\
\hline \multicolumn{7}{|c|}{ Gender } \\
\hline Male & 56 & 21 & 19 & $96(64)$ & \multirow{2}{*}{3.0} & \multirow{2}{*}{0.2} \\
\hline Female & 34 & 15 & 5 & $54(36)$ & & \\
\hline \multicolumn{7}{|c|}{ Education } \\
\hline Non-literate & 24 & 10 & 7 & $41(27.3)$ & \multirow{3}{*}{2.6} & \multirow{3}{*}{0.6} \\
\hline Primary and High School & 40 & 11 & 9 & $60(40)$ & & \\
\hline Secondary School and above & 26 & 15 & 8 & $49(32.6)$ & & \\
\hline \multicolumn{7}{|c|}{ Residence } \\
\hline Urban & 33 & 14 & 9 & $56(37.3)$ & \multirow{3}{*}{30.2} & \multirow{3}{*}{0.00} \\
\hline Urban slum & 46 & 3 & 10 & $59(39.3)$ & & \\
\hline Rural & 11 & 19 & 5 & $35(23.3)$ & & \\
\hline \multicolumn{7}{|c|}{ Socio-Economic status } \\
\hline Upper Class & 28 & 0 & 4 & $32(21.3)$ & \multirow{4}{*}{31.4} & \multirow{4}{*}{0.0} \\
\hline Upper Middle Class & 14 & 0 & 2 & $16(10.6)$ & & \\
\hline Lower Middle Class & 25 & 15 & 6 & $46(30.6)$ & & \\
\hline Upper Lower Class & 23 & 21 & 12 & $56(37.3)$ & & \\
\hline \multicolumn{7}{|c|}{ Duration Of Hypertension } \\
\hline $1-10 \mathrm{yrs}$ & 84 & 34 & 19 & $137(37.2)$ & \multirow{3}{*}{8.7} & \multirow{3}{*}{0.06} \\
\hline $10-20 \mathrm{yrs}$ & 5 & 1 & 5 & $11(7.3)$ & & \\
\hline$>20 \mathrm{yrs}$ & 1 & 1 & 0 & $2(1.3)$ & & \\
\hline \multicolumn{7}{|c|}{ Number of tablets taken } \\
\hline 1 & 66 & 26 & 17 & $109(72.6)$ & \multirow{4}{*}{2.3} & \multirow{4}{*}{0.5} \\
\hline 2 & 15 & 9 & 6 & $30(20)$ & & \\
\hline 3 & 3 & 1 & 1 & $5(3.3)$ & & \\
\hline 4 & 6 & 0 & 0 & $6(4)$ & & \\
\hline \multicolumn{7}{|c|}{ Medication Purchased } \\
\hline Government Pharmacy & 24 & 33 & 12 & $69(46)$ & \multirow{2}{*}{43.9} & \multirow{2}{*}{0.0} \\
\hline Private & 66 & 3 & 12 & $81(54)$ & & \\
\hline
\end{tabular}


Gowda, et al:: Assessment of Adherence to Anti-hypertensive Treatment among Patients

with Socio-economic status, residence and Place of Purchase of drugs $(P=0.0)$ (Table 6).

\section{DISCUSSION}

Hypertension, is a chronic disease that requires lifestyle interventions and pharmacotherapy for life, adherence to the therapy and its assessment is a major challenge to be addressed.

Out of 150, 90 (60\%) were having Low adherence, 36 (24\%) were having Medium adherence and 24 (16\%) High adherence for Drugs using Morisky Adherence scale.

In a hospital based study by Hema K et al. in Andhra Pradesh $(n=400)$, only $15.3 \%$ ( $n=61)$ of the participants were found to have high adherence to anti-hypertensive medication based on 8 point Morisky medication adherence scale. ${ }^{6}$ Study done by Kumarswamy RC et al. in a teaching hospital of Karnataka showed that $74 \%$ of the participants were adherent to the antihypertensive medication. ${ }^{7}$

In another community based study in Bangladesh by Khanam MA et al. $73.8 \%$ of the Participants were adherent to the medication. ${ }^{8}$ A hospital based study done by Ambaw AD et al. in Northwest Ethiopia $(n=384)$, $64.6 \%$ of the study participants were found to be adherent to their treatment. $^{9}$

In Present study their was no association with Age, gender, education, Occupation, duration of disease, number of tablets taken and place of purchase of drugs with adherence to drugs.

In contrast, a study by Rao BB et al. showed that adherence rate towards antihypertensive Medication was better among patient above 60 years of age $(67.2 \%)$ and this was found to be

statistically significant $(p=0.02) .{ }^{10}$ But study done at Mangalore in a tertiary care hospital by Kumar $\mathrm{N}$ et al. found that adherence was found to be good in the age group of $\leq 60$ but not statistically significant $(p=0.52) .{ }^{11}$ In contrast to the findings of the present study, Mazzaglia G et al. showed significant association between gender and adherence ( $p=$ $<0.001$ OR $(95 \% \mathrm{CI})=0.72(0.65-0.81)){ }^{12}$

In Present study Socio-economic status, residence and Place of Purchase of drugs were having influence on Adherence to drugs $(P=0.0)$, study done by Ahmad S et al. in Moradabad showed

statistical significance between SES and adherence where in participants belonging to upper middle class had better adherence compared to the lower middle class $(p=0.001)^{13}$

In present study their was association between number of drugs taken and adherence to drugs, Similar findings were reported from a study by Nagarkar AM et al. in which there was no significance found between adherence and number of drugs taken $(p=0.631) .{ }^{14}$

Patients who were hypertensive for a period of 5 years or more were 3 times more likely to be adherent compared with those suffering from hypertension for less than 5 years, emphasizing the fact that longer duration of the disease helps the patient to accept the diseased state as well as to adapt to the adherence behavior over time, consistent with findings from previous studies. Longer duration of hypertension helped these patients build up a habit of regularly consuming their pills. ${ }^{15}$

\section{CONCLUSION}

The study concludes with observation of $60 \%$ of Low adherence to drugs and statistically Significant results with Socio-economic status, However hypertension being a chronic and dynamic disease, adherence to the medication needs to be maintained continuously and fully optimized.

\section{ACKNOWLEDGEMENT}

The authors would like to thank Department of Community Medicine and Sri Siddhartha Medical College.

\section{CONFLICT OF INTEREST}

The authors declare that there are no conflicts of interest.

\section{RECOMMENDATIONS}

Health care Provider should incorporate a system to record the adherence to treatment and blood pressure control at every.

\section{ABBREVIATIONS}

MMAS 8: Morisky Medication Adherence Scale.

\section{REFERENCES}

1. Dave NS, Sharma RT, Kulkarni GR, SS. Therapy Compliance in Hypertension: Indian Clinicians Viewpoint. Int J Drug Dev and Res. 2017;9:8-11.

2. Subhasis BP, Sankara S, Kavumpurathu R, Thankappan. Assesement of adherence to Anti hypertensive treatment and its determinantsamong urban slum dwellers in Kolkata, India. Professor Asia Pac J Public Health. 2011. DOI: 10.1177/1010539511423568

3. Sathvik BS, Karibasappa MV, Nagavi BG. Self- reported medication adherence pattern of rural Indian patients with hypertension. Asian J Pharm Clin Res. 2013;6(Suppl 1):49-52.

4. Sabaté E. Adherence to long-term therapies: evidence for action. Geneva World Health Organization. 2003.

5. Blandford L, Dans PE, Ober JD, Wheelock C. Analyzing variations in medication compliance related to individual drug, drug class and prescribing physician. J Managed Care Pharm. 1999;5(1):47-5

6. Hema K, Padmalatha P. Adherence to medication among hypertensive patients attending a tertiary care hospital in Guntur, Andhra Pradesh. Indian J Basic Applied Med Res. 2014;4(1):451-6.

7. Kumaraswamy RC, Kauser MM, Jagadeesh MK, Kumar RU, Kumar SRV, Afreen $A$, et al. Study of determinants of non-adherence to anti-hypertensive medications in essential hypertension at a teaching hospital in Southern India. Chrismed J Health. 2015;4(1):57-60.

8. Khanam MA, Lindeboom W, Koehlmoos TLP, Alam DS, Niessen L, Milton AH. Hypertension: adherence to treatment in rural Bangladesh findings from a population-based study. Glob Health Action. 2014;7(1):25028.

9. Ambaw AD, Alemie GA, Yohannes SMW, Mengesha ZB. Adherence to antihypertensive treatment and associated factors among patients on follow up at university of Gondar Hospital, Northwest Ethiopia. BMC Public Health. 2012;12(1):282.

10. Rao BB, Kabra PR, Sreedhar M. Factors associated with adherence to antihypertensive treatment among hypertensive persons in an urban slum area of Hyderabad. Indian J Basic Applied Med Res. 2014;4(1):471-7.

11. Kumar N, Unnikrishnan B, Thapar R, Mithra P, Kulkarni V, Holla R, et al. Factors associated with adherence to antihypertensive treatment among patients attending a tertiary care hospital in Mangalore, South India. Int J Cur Res Rev. 2014;6(10):77-85.

12. Mazzaglia G, Ambrosioni E, Alacqua M, Filippi A, Sessa E, Immordino V, et al. Adherence to antihypertensive medications and cardiovascular morbidity among newly diagnosed hypertensive Patients. Circulation. 2009;120(16):1598605

13. Ahmad S. Assessment of adherence to antihypertensive treatment among patients attending a health care facility in North India. Int J Res Med. 2015;4(1):117 24.

14. Nagarkar AM, Gadhave SA, Sharma I, Choure I, Morisky D. Factors influencing medication adherence among hypertensive patients in a tertiary care hospital Pune, Maharashtra. National J Comm Med. 2013;4(4):559-63.

15. Jin J, Sklar GE, OhVMS, Li SC. Factors affecting therapeutic compliance: a review from the patient' sperspective. Ther Clin Risk Manag. 2008;4(1):269-86

Cite this article : Gowda CGK, Savitha RBB, lyengar K, Venkatesh P, Vinay KS. Assessment of Adherence to Antihypertensive Treatment among Patients Attending a Urban Health Care Facility of a Medical College, Tumkur. Int J Med Public Health. 2019;9(2):42-5. 